\title{
Comparison of vaginal misoprostol application versus curettage in treatment of early pregnancy failure: A randomization clinical trial study
}

\author{
Zoleikha Atarod ${ }^{1}$, Fatemeh Talebi ${ }^{1}$, Seyyed Abbas Hashemi ${ }^{2 \star}$ and Ali Kheradmand ${ }^{2}$ \\ ${ }^{1}$ Department of Obstetrics and Gynecology, Faculty of Medicine, Mazandaran University of Medical Sciences, Sari, Iran. \\ ${ }^{2}$ Faculty of Medicine, Student Research Committee, Mazandaran University of Medical Sciences, Sari, Iran.
}

Accepted 15 May, 2013

\begin{abstract}
In this study, we examined the impacts of vaginal misoprostol versus curettage in treatment of early pregnancy failure in women with first time pregnancy. Sixty (60) pregnant women (30 women in misoprostol and 30 subjects in curettage group) with mean age of $25.8 \pm 5.3$ were enrolled in the research. Early pregnancy failure (less than 12 weeks) was confirmed by trans-vaginal sonography. Eight hundred $(800 \mu \mathrm{g})$ of misoprostol was applied in posterior fornix of vagina and if there was failure to first prescription, second dose of misoprostol was applied after $24 \mathrm{~h}$. Data were analyzed by chi square and T-test. In misoprostol group; 5 women (17.2\%) in first $24 \mathrm{~h}, 14$ subjects $(48.2 \%)$ in $48 \mathrm{~h}$ and 3 participants $(10.3 \%)$ in 7 days had complete treatment. Seven women $(24.1 \%)$ had failure to misoprostol application. In curettage group, all of the patients received successful treatment. Hematocrit (HCT) before and after treatment in curettage group was $37.8 \pm 1.4$ and $35.6 \pm 1.3$, respectively while in misoprostol group, the HCT before treatment was $38.5 \pm 1.5$ and changed to $36.1 \pm 1.6$ after treatment. With considering type of therapy, there was significant differences between HCT level before and after treatment $(p=0.02)$. Negative $\beta$ hCG was observed after $3.3 \pm 0.5$ weeks in the curettage group while it was $3.5 \pm 0.5$ weeks for misoprostol group. There was no significant change in this regard $(p=0.3)$. Application of vaginal misoprostol can be used as treatment in early pregnancy failure but curettage is superior.
\end{abstract}

Key words: Early pregnancy failure, misoprostol, curettage.

\section{INTRODUCTION}

Early pregnancy failure is a common complication, and about one of every four women experiences it. The standard method of encounter with early pregnancy failure has been dilatation and curettage Graziosi et al., 2004; McNamee et al., 2012; Kulier et al., 2011). In the past, considering the speed and effectiveness of surgical treatment, surgery was considered a standard treatment for miscarriage. But due to complications such as bleeding, damage to the uterus (uterine perforation) and cervical injury or Asherman's syndrome, it seems non-surgical treatment for miscarriage is more appropriate (Tang and Ho, 2006).

Misoprostol is a synthetic analog of prostaglandin E1. It has been widely used for medical abortion, cervical preparation before surgical abortion, induction of labor and is also used to terminate pregnancy (Graziosi et al., 2005). Misoprostol was considered as a cheap, easy, available and noninvasive alternative for abortion (Wood and Brain,

*Corresponding author. E-mail: abbas.hashemi30@gmail.com. Tel: 00989112581083. Fax: 00981513543248. 
2002). According to these advantages, misoprostol has been considered as a well treatment option for early pregnancy failure (Ngai et al., 2001). In 50 to 99\% of women with early pregnancy failure, treatment with misoprostol as an alternative to abortion, lead to withdrawal of gestation contents to 14 weeks of pregnancy (Carbonell et al., 2001; Carbonell et al., 1998; Creinin et al., 1997).

In many countries, recommended dose of misoprostol for termination of early pregnancy failure is 800 to 1000 $\mu \mathrm{g}$ (Sahin et al., 2001; Muffley et al., 2002; Kovavisarach and Sathapanachai, 2002; Herabutya and OPrasertsawat, 1997; Wood and Brain, 2002; Jain et al., 1999; Barceló et al., 2012). But they have reported many dose-related side effects such as nausea, vomiting, diarrhea, abdominal pain, chills and fever (Prasartsakulchai and Tannirandorn, 2004). However, drug therapies can reduce complications, hospitalization time and costs. The aim of this study was to compare vaginal misoprostol with curettage in the treatment of early pregnancy failure.

\section{PATIENTS AND METHODS}

The ethics committee of Mazandaran University of Medical Sciences approved this study (register number $=1200$ ). The study population voluntarily participated in this investigation. Written consent was obtained from the participants for publication of the research outcomes. All subjects signed consent forms in the presence of a witness for all evaluations and treatments applied. Study participants consisted of pregnant women less than 12 weeks who have been visited in Imam Khomeini hospital (University hospital) Sari, Iran. Inclusion criteria were nulligravid women aged 18 to 45 years, with confirmation of early pregnancy failure by trans-vaginal sonography. All patients were divided in two groups (30 patients in each study arm) based on randomization. One group received vaginal misoprostol (medical therapy) and the patients in the other group underwent dilation and curettage (surgical group).

Patients had stable vital signs without any infection or history of asthma and allergy to misoprostol. They did not have any contraindications for prostaglandins. Patients who had side effects like nausea and severe vomiting (more than four times per day or with dehydration), severe bleeding, diarrhea with dehydration were withdrawn from the study and categorized as complication group.

For cases which had been selected for dilation and curettage, complete blood count (CBC) and rhesus (Rh) were checked. If $\mathrm{Rh}$ was negative, $300 \mu \mathrm{g}$ rhogam was injected and then dilation and curettage were performed by researcher. CBC and trans-vaginal sonography were checked $24 \mathrm{~h}$ after dilation and curettage again. The same procedure was performed for misoprostol group (checking $\mathrm{CBC}$ and $\mathrm{Rh}$ ). If the $\mathrm{Rh}$ was negative, $300 \mu \mathrm{g}$ rhogam was injected and then $800 \mu \mathrm{g}$ misoprostol was applied in posterior fornix of vagina. All patients were controlled for signs such as bleeding, nausea, vomiting, fever and chilling. If there were no alarm signs, patients were discharged after teaching all alarm signs.

The day after treatment, patients were visited again and transvaginal sonography was done by sonographist. Treatment was considered as successful if there were no residues (meaning if the thickness of the uterine cavity was less than $30 \mathrm{~mm}$, patients were discharged and if the sac was still intact or the thickness of the uterine cavity was more than $30 \mathrm{~mm}$, they were offered an additional dosage of vaginal misoprostol or surgical uterine evacuation), then hematocrit (HCT) was checked. If there were pregnancy residue without bleeding, once more, $800 \mu \mathrm{g}$ misoprostol was applied in posterior fornix. If patient did not have any signs, they were discharged and after $24 \mathrm{~h}$ trans-vaginal sonography was applied. If there were residues and failure to medical therapy after one week, patients were prepared for dilatation and curettage in operation room under general anesthesia.

Patients were referred to the Imam Khomeini Hospital Laboratory in order to check HCT if medical therapy was successful, and HCT level was compared in two groups. Then, $\beta$ hCG was controlled every week and the time was needed for negative $\beta$ hCG compared in the two groups. Data were presented as mean \pm standard deviation (SD). For statistical analysis, statistical package for social sciences (SPSS) software (Version 16, Chicago, IL, USA) was used. Quantitative variables were compared in two groups by T-test and qualitative once by chi square test. $\mathrm{P}<0.05$ was defined as statistically significant.

\section{RESULTS}

Study population included 30 patients in surgical therapy group (the first group) and 30 people in medical therapy group (treatment with misoprostol). The mean age for all cases was $25.8 \pm 5.3 ; 26.3 \pm 5.4$ in the medical therapy and $25.3 \pm 5.3$ in surgical group $(p=0.4)$ (Table1). There were no history of diseases such as coagulation disorder, sensibility with prostaglandins and history of asthma. Baseline characteristics were 16 cases $(26.7 \%)$ with blighted ovum, 37 cases (61.6\%) with missed abortion, and the rest had pregnancy residue. In surgical group with curettage, all cases had successful treatment which was confirmed by trans-vaginal sonography, and we did not see any pregnancy residue, whereas in medical therapy, 7 cases $(24.1 \%)$ had failure to therapy.

In medical therapy group, 5 cases $(17.3 \%)$ received just one dose $(800 \mu \mathrm{g})$ of misoprostol and 24 cases $(82.7 \%)$ received two time misoprostol with $24 \mathrm{~h}$ interval. Successful treatment in medical group was observed in 5 cases (17.3\%) within $24 \mathrm{~h}, 14$ cases $(48.2 \%)$ within $48 \mathrm{~h}$ and 3 cases (10.3\%) within 7 days. For 7 cases (who had failure in medical therapy), dilatation and curettage was prescribed and 1 case (3.4\%) after the first dose of misoprostol withdrawn out of study because of unstable vital signs, and then was prepared for urgency dilatation and curettage. In all, $75.9 \%$ cases medical therapy was successful.

Uterus tissues existence and bleeding time after medical therapy with misoprostol was $7.9 \pm 3.4 \mathrm{~h}$ after treatment. HCT before and after treatment in surgical group was $37.8 \pm 1.4$ and $35.6 \pm 1.3$, respectively whereas in medical group the HCT before treatment was $38.5 \pm$ 1.5 and decreased to $36.1 \pm 1.6$ after therapy. Difference between HCT level before and after treatment was significantly related with the kind of therapy $(p=0.02)$ (Table 2). After $3.3 \pm 0.5$ weeks, we had negative $\beta$ hCG in the surgical group while it was $3.5 \pm 0.5$ weeks for medical group. There were no significant differences between these variables $(p=0.3)$ (Table 1). 
Table 1. Characteristics of study population and $\beta$ hCG level.

\begin{tabular}{lccc}
\hline Treatment & Curettage group & Misoprostol group & P value \\
\hline Age & $25.3 \pm 5.3$ & $26.3 \pm 5.4$ & 0.4 \\
Negative $\beta$ hCG (weeks) & $3.3 \pm 0.5$ & $3.5 \pm 0.5$ & 0.3 \\
\hline
\end{tabular}

Table 2. Mean values of HCT before and after treatment.

\begin{tabular}{lccc}
\hline Treatment & HCT before therapy & HCT after therapy & P value \\
\hline Curettage group & $37.8 \pm 1.4$ & $35.6 \pm 1.3$ & 0.02 \\
Misoprostol group & $38.5 \pm 1.5$ & $36.1 \pm 1.6$ & 0.02 \\
\hline
\end{tabular}

None of the patients in curettage group had any compliant such as anesthesia complications, perforation, urethritis, bleeding and cervical injury. Patients vital signs after surgery were stable in curettage group while medical group 6 cases $(19.8 \%)$ had complications, including 1 case $(3.3 \%)$ with severe bleeding and unstable vital signs, 3 cases (10\%) with nausea and mild vomiting ( 1 to 2 times per day without dehydration ) and 2 cases $(6.6 \%)$ with mild diarrhea (1 to 2 time per day).

\section{DISCUSSION}

In this clinical trial study, we compared the effect of application of vaginal misoprostol versus curettage in treatment of early pregnancy failure in women with first time pregnancy. In the current investigation, we showed, in misoprostol group; 5 patients (17.2\%) in first $24 \mathrm{~h}, 14$ patients (48.2\%) in $48 \mathrm{~h}$ and 3 participants (10.3\%) in 7 days had complete evacuation of uterine content. In patients that underwent dilatation and curettage, all of them received successful treatment. In this relation, Kovavisarach and Sathapanachai (2002) compared the effect of misoprostol and placebo in induction of abortion in women in first trimester. They indicated that the induction of abortion in misoprostol group was $63 \%$ and in placebo $18.5 \%$.

Graziosi et al. (2004) examined the effects of misoprostol and curettage in 79 women with early pregnancy failure. They reported in misoprostol and curettage group; $53 \%$ and $96 \%$ had complete delivery without the aid of surgery, respectively. In their research, $60 \%$ of women used misoprostol for second time. But in contrast with our study, $77 \%$ of the participants used misoprostol for second time which can be related to the first pregnancy of these subjects. They indicated that complications were observed in $25 \%$ of the misoprostol group. Likewise in this study, complications were noted in 6 cases (19.8\%) including severe bleeding and unstable vital signs $(3.3 \%)$, nausea and mild vomiting (10\%) and mild diarrhea $(6.6 \%)$.
Odeh et al. (2010) investigated 81 women with early pregnancy failure, with the mean age of 29 years. They revealed that those patients who received one dose of misoprostol $(800 \mu \mathrm{g})$ had $88.9 \%$ achievement in therapy and those who received second dose since failure to first use had $66.7 \%$ success. In consistency with the current study, $17.3 \%$ had successful treatment in their first experience. Carbonell et al. $(1998,2001)$ used misoprostol (1000 $\mathrm{\mu g}$ vaginal) in three consequent doses every $24 \mathrm{~h}$ and elucidated that this could be accompanied with complete abortion in $93 \%$ of the patients. The mean time of uterus tissue extraction existence and bleeding was $8.1 \mathrm{~h}$ in their study but this time in our study was $7.9 \mathrm{~h}$.

\section{Conclusion}

Our study revealed that vaginal misoprostol $(800 \mu \mathrm{g})$ can be used for termination in treatment of early pregnancy failure in pregnant women in the first trimester. Our results showed that curettage is superior to vaginal misoprostol in the evacuation of early pregnancy failure. But vaginal misoprostol can be considerable since it decreases the rate of curettage and has low complication rate.

\section{ACKNOWLEDGEMENT}

We acknowledge Mazandaran University of medical sciences for their support through grant.

\section{REFERENCES}

Graziosi GC, Mol BW, Reuwer PJ, Drogtrop A, Bruinse HW (2004). Misoprostol versus curettage in women with early pregnancy failure after initial expectant management: a randomized trial. Hum. Reprod. 19(8):1894-1899.

McNamee K, Dawood F, Farquharson RG (2012). Thrombophilia and early pregnancy loss. Best Pract. Res. Clin. Obstet. Gynaecol. 26(1):91-102.

Kulier R, Kapp N, Gülmezoglu AM, Hofmeyr GJ, Cheng L, Campana A 
(2011). Medical methods for first trimester abortion. Cochrane Database Syst. Rev. Nov 9;(11):CD002855.

Tang OS, Ho PC (2006). The use of misoprostol for early pregnancy failure. Curr. Opin. Obstet. Gynecol. 18(6):581-586.

Graziosi GC, Bruinse HW, Reuwer PJ, van Kessel PH, Westerweel PE, Mol BW (2005). Misoprostol versus curettage in women with early pregnancy failure: impact on women's health-related quality of life. A randomized controlled trial. Hum. Reprod. 20(8):2340-2347.

Wood SL, Brain PH (2002). Medical management of missed abortion: a randomized clinical trial. Obstet Gynecol 99:563-566.

Ngai SW, Chan YM, Tang OS, Ho PC (2001). Vaginal misoprostol as medical treatment for first trimester spontaneous miscarriage. Hum. Reprod. 16:1493-1496.

Carbonell JL, Rodriguez J, Aragon S (2001). Vaginal misoprostol 1000 microgram for early abortion. Contraception 63:131-136.

Carbonell JL, Varela L, Velazco A, Cabezas E, Tanda R, Sanchez C (1998). Vaginal misoprostol for late first trimester abortion. Contraception 57:329-333.

Creinin MD, Moyer R, Guido R (1997). Misoprostol for medical evacuation of early pregnancy failure. Obstet. Gynecol. 89:768-762.

Sahin HG, Sahin HA and Kocer M (2001). Randomized outpatient clinical trial of medical evacuation and surgical curettage in incomplete miscarriage. Eur. J. Contracept. Reprod. Health Care $6: 141-144$.
Muffley PE, Stitely ML, Gherman RB (20020. Early intrauterine pregnancy failure: a randomized trial of medical versus surgical treatment. Am. J. Obstet. Gynecol. 187:321-325.

Kovavisarach E, Sathapanachai U (2002). Intravaginal 400 microg misoprostol for pregnancy termination in cases of blighted ovum: a randomized controlled trial. Aust. NZ. J. Obstet. Gynaecol. 42:161163.

Herabutya Y, O-Prasertsawat P (1997). Misoprostol in management missed abortion. Int. J. Gynaecol. Obstet. 56:263-266.

Jain JK, Meckstroth KR, Mishell DR (1999). Early pregnancy termination with intravaginally administered sodium chloride solution moistened misoprostol tablet. Am. J. Obstet. Gynecol. 181:1386-1391.

Barceló F, De Paco C, López-Espín JJ, Silva Y, Abad L, Parrilla JJ (2012). The management of missed miscarriage in an outpatient setting: 800 versus $600 \mu \mathrm{g}$ of vaginal misoprostol. Aust. NZ. J. Obstet. Gynaecol. 52(1):39-43.

Prasartsakulchai C, Tannirandorn Y (2004). A Comparison of Vaginal Misoprostol $800 \mu \mathrm{g}$ Versus $400 \mu \mathrm{g}$ in Early Pregnancy Failure: A Randomized Controlled Trial. J. Med. Assoc. Thai 87:18-23.

Odeh M, Tendler R, Kais M, Maximovsky O, Ophir E, Bornstein J (2010). Early pregnancy failure: factors affecting successful medical treatment. Isr. Med. Assoc. J. 12(6):325-258. 